\title{
Separation and concentration of succinic adic from multicomponent aqueous solutions by nanofiltration technique
}

\author{
Jerzy Antczak, Justyna Regiec, Krystyna Prochaska* \\ Poznan University of Technology, Institute of Chemical Technology and Engineering, pl. M. Skłodowskiej-Curie 2, \\ 60-965 Poznań, Poland \\ "Corresponding authors: e-mail: krystyna.prochaska@put.poznan.pl
}

\begin{abstract}
This paper applies the determined suitability of nanofiltration (NF) membrane separation for selective isolation and concentration of succinic acid from aqueous solutions which are post-fermentation multicomponent fluids. The study analyzed the influence of concentration and the $\mathrm{pH}$ of the separated solutions on the efficiency and selectivity of NF process that runs in a module equipped with a ceramic membrane. Moreover, the effect of applied transmembrane pressure on the retention of succinic acid and sodium succinate has been studied. The investigations have shown that in the used NF module the retention of succinic acid salt is equal almost $50 \%$ in the case of a three-component model solution, although the degree of retention depends on both the transmembrane pressure and the initial concentration of separated salt.
\end{abstract}

Keywords: glycerol bioconversion, fermentation broth, succinic acid, nanofiltration, ceramic membrane.

\section{INTRODUCTION}

The worldwide production of biodiesel is growing steadily $^{1}$. From year to year the amount of residual glycerol increases, which is one of the main by-products in the process for obtaining biofuels ${ }^{2}$. So the technologies allowing for the development of waste glycerol are of great interest. Many research centers focused on biotechnological processing of glycerol by microbial bioconversion. Through appropriate relation of microorganisms clones it is possible to obtain low molecular weight organic compounds which are useful chemical materials ${ }^{3}$. In this way, waste glycerol is an alternative to petroleum raw material in chemical synthesis technologies. Furthermore an additional benefit from the bioconversion of waste glycerol is lower pollution of the environment. One of the products of bioconversion of glycerol is succinic acid, an important raw material in the pharmaceutical industry, food industry production of plastics. Besides succinic acid, there are different organic acids in the fermentation broth, such as formic acid, acetic acid, citric acid, along with mineral salts and minor amounts of polyols and proteins ${ }^{4-6}$. One of the most important and usually the most expensive step of succinic acid production by bioconversion of glycerol is its selective isolation from other compounds from post-fermentation broth.

Among available techniques for the separation of low molecular weight organic compounds from fermentation broths, membrane techniques play an important role, including pressure processes ${ }^{7-9}$. However, taking into account that the organic acids, generally have very low values of molecular weight (MW), MF and UF membranes may not reject them effectively enough. On the other hand, NF membranes with two retention mechanisms (i.e. the electrostatic repulsion in the case of dissociated form of acids (above $\mathrm{pKa}$ ) and the sieving effect due to the molecular size of the neutral form of the organic acids (below $\mathrm{p} K a)$ ) are capable of rejecting these compounds.

It should be stressed that the efficiency of retention of weak acids (as dicarboxylic acids) in the NF process is influenced strongly by $\mathrm{pH}$ variation in the feed solution as well as the value of the molecular weight of the separated compounds. Their retention in the NF process will be high in the ionized form. Thus, the organic acid rejection increases significantly at $\mathrm{pH}$ levels above the acidity constant $(\mathrm{pKa})$, but the rejection decreases at $\mathrm{pH}$ levels below $\mathrm{pKa}$ (when the acids are in the neutral form).

Analysis of changes in the degree of dissociation of succinic acid depending on the $\mathrm{pH}$ of the solution (Fig. 1) shows, that in solutions of a $\mathrm{pH}<2$, succinic acid is completely undissociated, which means that it is in the form of neutral molecules. At $2<\mathrm{pH}<8$ the solution contains both the undissociated acid molecules and succinate anions and hydrogen succinate. However, at $\mathrm{pH}>8$, in an aqueous solution of a salt of succinic acid the ionic form are only present. Thus, for the separation and concentration of succinic acid by the NF technique, optimal for acid solution seems to be $\mathrm{pH} 2$, and for alkaline solution $\mathrm{pH}>8$.

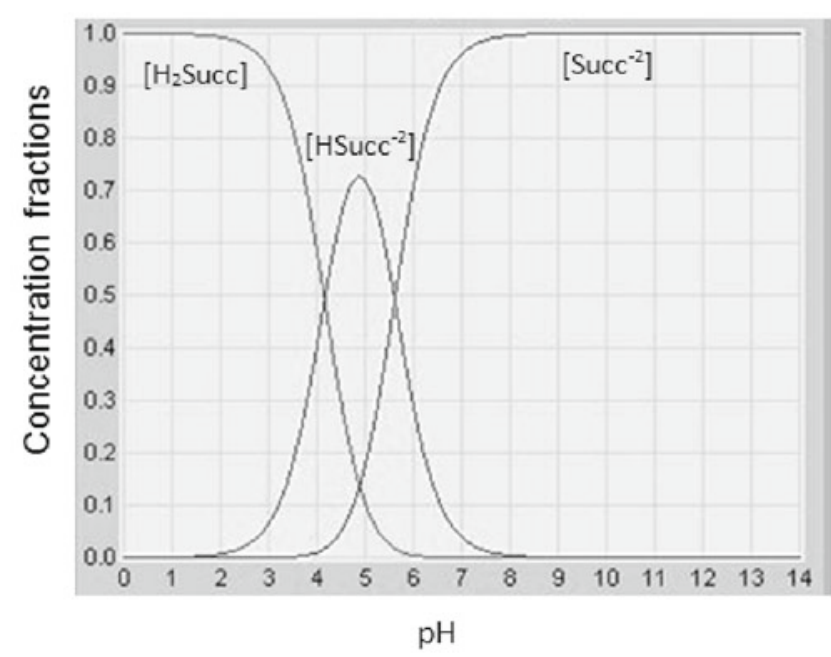

Figure 1. Ionic fraction of succinic acid as function of $\mathrm{pH}^{\mathbf{1 0}}$

The aim of the research presented in this paper was to determine suitability of NF membrane separation for selective isolation and concentration of succinic acid from model aqueous solutions serving as post-fermentation multicomponent fluids. The study analyzed an influence of concentration and $\mathrm{pH}$ of separated solutions 
on efficiency and selectivity of NF process that runs in the module equipped with a ceramic membrane of tubular configuration. Moreover, the effect of applied transmembrane pressure on the retention of succinic acid and sodium succinate has been investigated.

\section{EXPERIMENTAL PART}

\section{Test equipment}

To study the separation and concentration of succinic acid by nanofiltration technique the pilot plant shown in the Figure 1 was used. Membrane module was equipped with tubular ceramic mono-channel membrane (active layer of $\mathrm{TiO}_{2}$ ) (TAMI Industries, France) with cut-off $450 \mathrm{Da}$ and the effective surface area equal to $0.0125 \mathrm{~m}^{2}$. All of the experiments were carried out at room temperature and at transmembrane pressure (TMP) from the range $0.4 \div 1.5 \mathrm{MPa}$.

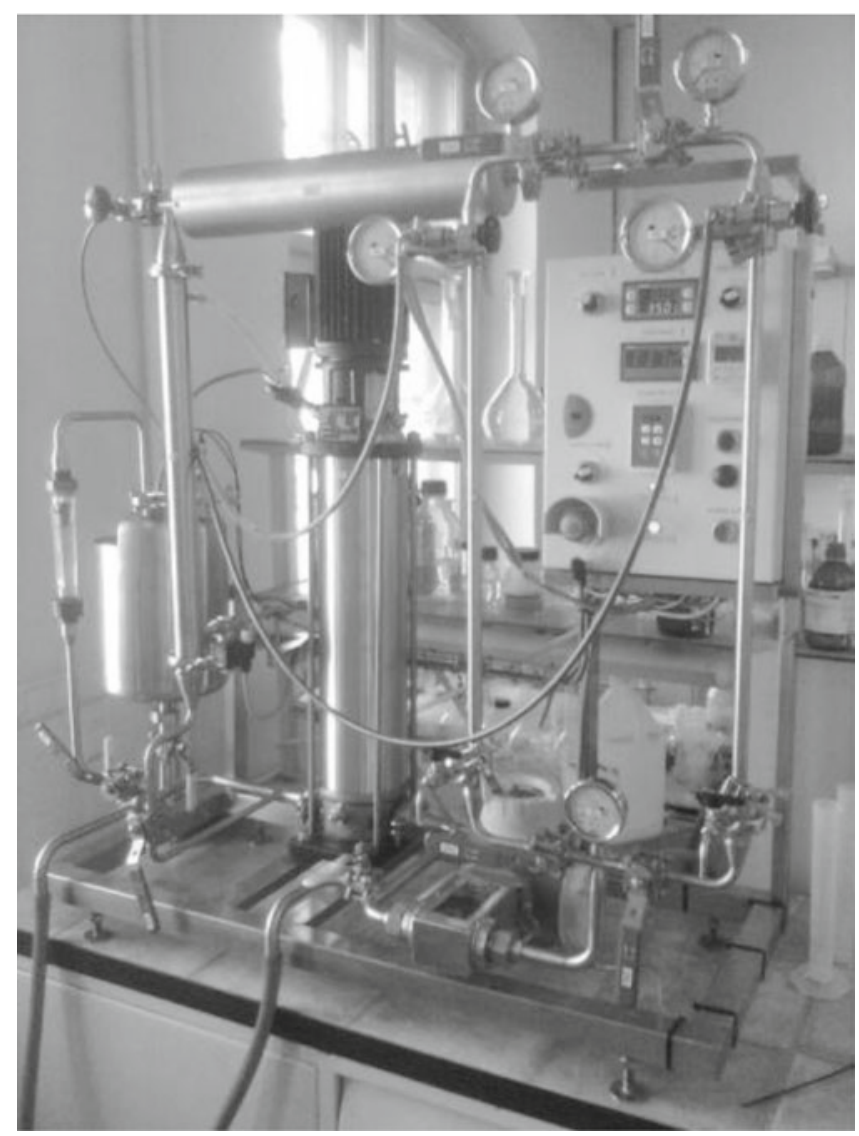

Figure 2. NF module used in investigation

\section{Reagents}

For studies there were used: succinic acid (Succ) (Sigma-Aldrich), citric acid (Cit) (Fluka), acetic acid (Ac) (Fluka), all compounds of analytical purity. To preparation of all solutions the deionized water with a conductivity not exceeding $3 \mu \mathrm{S} \cdot \mathrm{cm}^{-1}$ was used. Solutions $\mathrm{pH}$ was determined by adding an appropriate amount of sodium hydroxide (Sigma-Aldrich).

\section{NF process}

To the NF process $10 \mathrm{dm}^{3}$ of stock solution (feed $-\mathrm{F}$ ) were prepared. The process was carried out in a closed system. All of 1.5 min samples of the permeate $(\mathrm{P})$ were collected in the volumes of $0.05 \mathrm{dm}^{3}$ and $0.1 \mathrm{dm}^{3}$ for transmembrane pressure $0.4 \mathrm{MPa}$ and 1 (or 1.5) $\mathrm{MPa}$,
Table 1. Characterization of solutions used in NF process

\begin{tabular}{|c|c|c|}
\hline $\begin{array}{l}\text { Solution } \\
\text { number }\end{array}$ & $\mathrm{pH}$ & Components of solution \\
\hline 1 & $\leqslant 2.8$ & $\begin{array}{l}\text { a) } 1 \% \text { Succ } \\
\text { b) } 3 \% \text { Succ }\end{array}$ \\
\hline 2 & $\leqslant 2.8$ & $\begin{array}{l}\text { a) } 1 \% \text { Succ }+0.1 \% \text { Cit } \\
\text { b) } 3 \% \text { Succ }+0.3 \% \text { Cit }\end{array}$ \\
\hline 3 & $\leqslant 2.8$ & a) $1 \%$ Succ $+0.1 \%$ Ac \\
\hline 4 & $\leqslant 2.8$ & $\begin{array}{l}\text { a) } 1 \% \text { Succ }+0.1 \% \text { Cit }+0.1 \% \text { Ac } \\
\text { b) } 3 \% \text { Succ }+0.3 \% \text { Cit }+0.3 \% \text { Ac }\end{array}$ \\
\hline 5 & $\geqslant 10$ & $\begin{array}{l}\text { a) } \quad 1 \% \mathrm{Na}_{2} \text { Succ } \\
\text { b) } 3 \% \mathrm{Na}_{2} \text { Succ }\end{array}$ \\
\hline 6 & $\geqslant 10$ & $\begin{array}{l}\text { a) } 1 \% \mathrm{Na}_{2} \text { Succ }+0.1 \% \mathrm{Na}_{3} \mathrm{Cit} \\
\text { b) } 3 \% \mathrm{Na}_{2} \text { Succ }+0.3 \% \mathrm{Na}_{3} \text { Cit }\end{array}$ \\
\hline 7 & $\geqslant 10$ & a) $1 \% \mathrm{Na}_{2}$ Succ $+0.1 \% \mathrm{NaAc}$ \\
\hline 8 & $\geqslant 10$ & $\begin{array}{l}\text { a) } 1 \% \mathrm{Na}_{2} \text { Succ }+0.1 \% \mathrm{Na}_{3} \mathrm{Cit}+0.1 \% \\
\text { b) } \\
\text { b) } \\
3 \% \mathrm{Na}_{2} \text { Succ }+0.3 \% \mathrm{Na}_{3} \mathrm{Cit}+0.3 \% \\
\mathrm{NaAc}\end{array}$ \\
\hline
\end{tabular}

respectively. The samples of the retentate $(\mathrm{R})$ were collected after the filtration of the feed in an amount of respectively $0.5 \mathrm{dm}^{3}$ for TMP $=0.4 \mathrm{MPa}$ and $1 \mathrm{dm}^{3}$ for TMP $=1$ or $1.5 \mathrm{MPa}$. The end of the process takes place after the collection of $2 \mathrm{dm}^{3}$ permeate from the NF module. Before and after each experiment of nanofiltration of the examined solutions the flux of deionized water was measured. All of the experiments were carried out at room temperature.

\section{Analyses}

The content of mono- and dicarboxylic acids and their salts in the starting solution and in the retentate and permeate fractions obtained in the NF was determined using high performance liquid chromatography HP Agilent 1100 Series (Germany), equipped with autosampler, interface (HP 35900), RI Detector (HP 1047A), pump (HP1050), and separating column Rezex ROA-OrganicAcid $\mathrm{H}+(8 \%)$, Phenomenex®. The eluent of $2.5 \mathrm{mM}$ $\mathrm{H}_{2} \mathrm{SO}_{4}$ solution was constantly brought to a rate of 0.9 $\mathrm{ml} \cdot \mathrm{min}^{-1}$. Column temperature and the temperature at the input to the detector was equal to $40^{\circ} \mathrm{C}, \mathrm{P}=0.56$ MPa. All samples were acidified to $\mathrm{pH} \leq 2$ by addition of $100 \mu \mathrm{l} 25 \% \mathrm{H}_{2} \mathrm{SO}_{4}$ to $1000 \mu \mathrm{l}$ of sample before analysis.

\section{RESULTS AND DISCUSSION}

Before proceeding to NF research the hydrodynamic permeability coefficient (Lp) of the applied ceramic membrane was determined $\left(\mathrm{Lp}=12.26 \cdot 10^{-2}\right.$ $\left.\mathrm{dm}^{3} \cdot \mathrm{m}^{-2} \cdot \mathrm{s}^{-1} \cdot \mathrm{MPa}^{-1}\right)$.

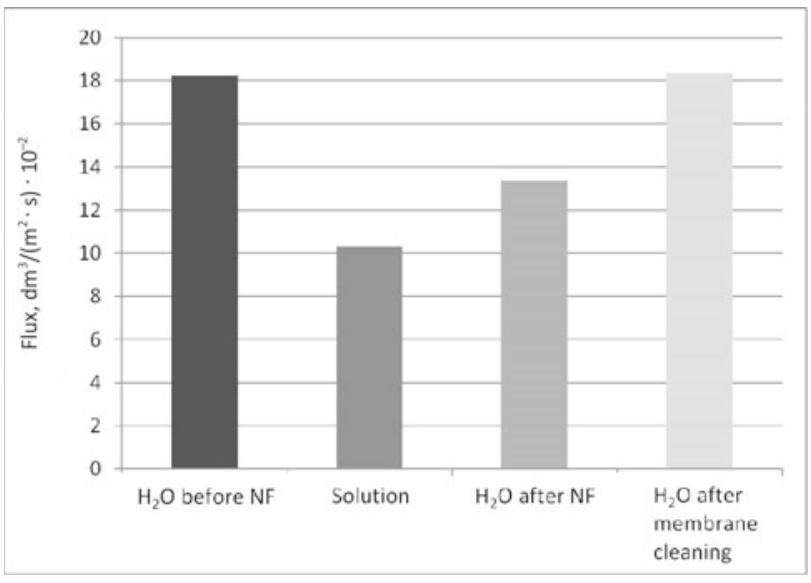

Figure 3. The permeate flux obtained in NF process at $\mathrm{TMP}=1.5 \mathrm{MPa}$ 
Prior to each experiments of NF of acid solutions, the initial permeability of water (at TMP equal to $1.5 \mathrm{MPa}$ ) was tested and after each experiment the ceramic membrane was cleaned according to the following procedure recommended by the producer: (a) washing with ultrapure water $\left(10\right.$ min at $\left.30^{\circ} \mathrm{C}\right),(\mathrm{b})$ alkaline bath $-1 \%$ of sodium hydroxide $\left(45 \mathrm{~min}\right.$ at $\left.70^{\circ} \mathrm{C}\right)$, (c) washing with ultrapure water $\left(10 \mathrm{~min}\right.$ at $\left.50^{\circ} \mathrm{C}\right)$, (d) washing with ultrapure water $\left(10 \mathrm{~min}\right.$ at $\left.40^{\circ} \mathrm{C}\right)$ until the $\mathrm{pH}$ neutralization, (e) acid bath $-0.5 \%$ nitric acid $\left(10 \mathrm{~min}\right.$ at $\left.50^{\circ} \mathrm{C}\right)$, (f) washing with ultrapure water $\left(10 \mathrm{~min}\right.$ at $\left.40^{\circ} \mathrm{C}\right),(\mathrm{g})$ washing with ultrapure water $\left(10 \mathrm{~min}\right.$ at $\left.30^{\circ} \mathrm{C}\right)$ until the $\mathrm{pH}$ neutralization. The exemplary results presented in Figure 3 indicate that the fouling of membrane was removed successfully. As a result of the cleaning process the initial water permeability was recovered.

Figures 4 and 5 show the permeate flux obtained in the NF of aqueous solutions of acids and salts after 20 minutes of operation. These results allow to compare the efficiency of the NF module (quantity of filtrate) at different TMP equal to $0.4,1.0$ and $1.5 \mathrm{MPa}$, respectively. In the case of all systems investigated higher operating pressure generally results in higher permeate flux, irrespective of the composition of separated solutions. The data presented in Figure 5 which illustrates the performance of the NF process for 1, 2 and 3 -component solutions of salts, indicate that an increase of transmembrane pressure from 0.4 to $1.5 \mathrm{MPa}$ in the case of single-solution results in even a fivefold increase of obtained permeate flux. However, it is advised that the operating pressure should be controlled so that it would not give a very high initial flux which leads to a poor overall performance of the membrane ${ }^{7}$.

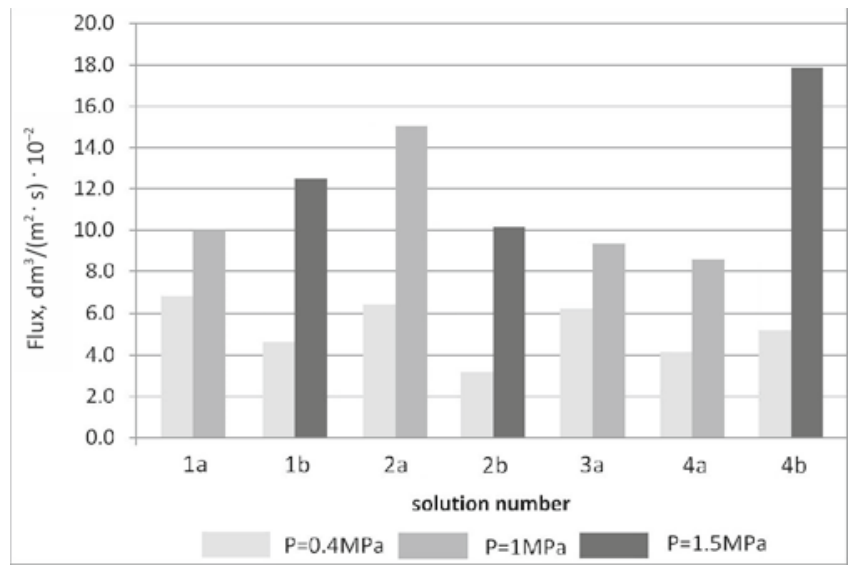

Figure 4. The permeate flux in NF of acids solutions

Another factor affecting the efficiency of the NF process is the composition of separated solutions. In most cases, with increased amounts of the components the flux decreases, however, observed changes are only minor. Analysing the performance of NF process separation of acid solutions (Fig. 4) it should be noted that the volume of the flux depends not only on the amount of ingredients in a separated solution, but also on the type of separated acids.

Taking into account the cut-off $450 \mathrm{Da}$ of applied ceramic membrane and the molecular weight of separated acids (succinic acid: 118.09 Da, citric acid: 192.12 Da, acetic acid: $60.05 \mathrm{Da}$ ) it is obvious that the retention

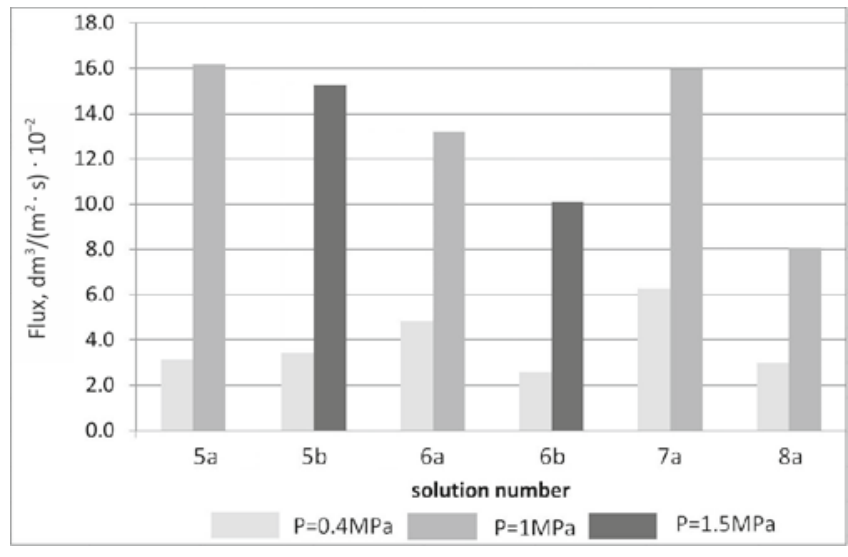

Figure 5. The permeate flux in NF of salts solutions

mechanism in systems considered was connected with the electrostatic repulsion between separated species and the charged membrane surface. The sieving effect was of secondary importance and can be omitted. Moreover, on the basis of literature data ${ }^{12}$ we can assume that the charge of a ceramic membrane surface applied in our investigation becomes more negative when $\mathrm{pH}$ increases. Thus, in the case of filtration of alkaline solution $(\mathrm{pH}>8)$ an increase in the electrostatic repulsion between solute and membrane should be occurred and as consequence an increase of retention of negatively charged organic solutes should be observed.

Figures 6 and 7 summarize the values of the retention degree of individual components, designated by study of the NF separation of 1,2 and 3 component-solutions. Analysing the results illustrated in Figures 6 and 7 it should be noted that $\mathrm{pH}$ of separated solutions was the greatest effect on the retention of acid (or salt) in studied sets. In the case of NF process of solutions containing undissociated acid, the degree of succinic acid retention is only a few \% (2-6\%) and essentially does not depend on the composition of the separated solution or initial concentration. Slightly higher retention in comparison of $6-10 \%$ citric acid was observed. However, the change of $\mathrm{pH}$ of the separated solution from the acidic $(\mathrm{pH} \leq 2.8)$, where they are completely undissociated acids, to alkaline $(\mathrm{pH} \geq 10)$, where the acids are in the form of dissociated salts, results in strong retention increase, both of sodium succinate and sodium citrate. It should also be noted that in the case of NF of alkaline solution a significant effect of solution concentration on the retention degree was observed. As shown in 1 and 2 component-sets, the retention degree decreases to a half nearly when the initial concentration of the solution varies from $1 \%$ to $3 \%$.

The retention of acetic acid, however, was zero irrespective of the composition of the test solution, which means that the monocarboxylic acid, in constant to diand tricarboxylic acid is completely passes by the ceramic membrane used in experiments.

In all tested systems a strong influence of the transmembrane pressure on the retention of ingredients was observed. Our results presented in Figures 6 and 7 indicated that with the increase of the value of TMP the degree of retention decreases, whereas the increase of degree of retention with increasing amounts of the components in separated solution is observed. Similar effect was described by S.H. Kang who investigated the 


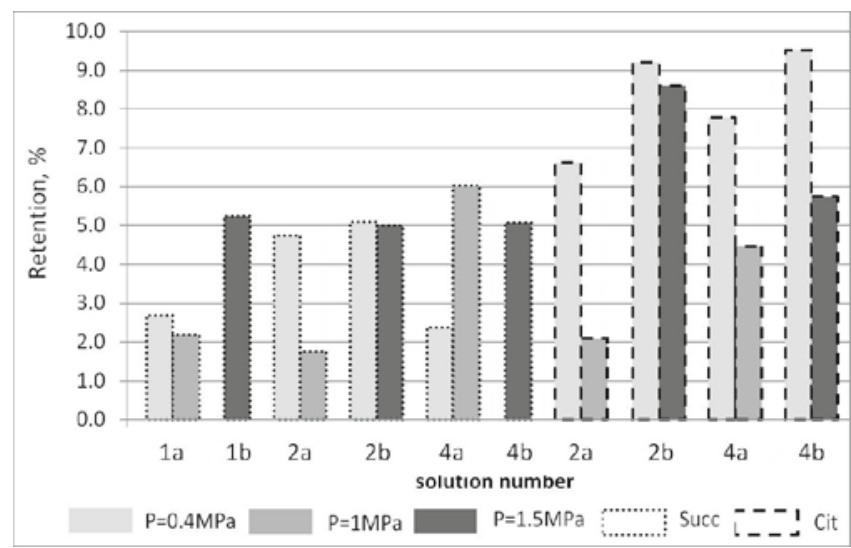

Figure 6. The retention of acids solutions components during NF process

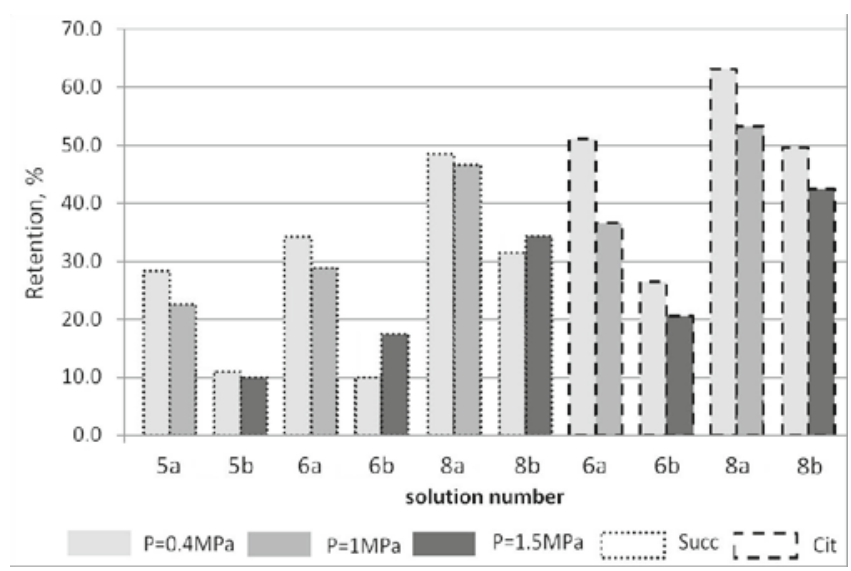

Figure 7. The retention of salts solutions components during NF process

removal of organic acid salts from simulated fermentation broth containing succinate ${ }^{\mathbf{1 1}}$. In the cited paper succinate rejection in multi-salt solutions was observed much higher than that in its single-salt solution, which was quite opposite to the cases of the monovalent acid salts involved. According to the Authors this could be well described by the facilitated transport of the monovalent anions due to Donnan effect in the presence of succinate, a divalent anion.

\section{CONCLUSIONS}

The performed study shows that the retention of succinic acid in the NF process of multicomponent solutions is determined mainly by the $\mathrm{pH}$ of the separated solution. Retention of succinic acid in NF module equipped with a ceramic membrane can be equal to almost $50 \%$, although the degree of retention depends on the $\mathrm{pH}$ of the solution, applied transmembrane pressure and the number of components in a separated solution. In the case of applied ceramic membrane the fouling of membrane can be removed successfully.

\section{ACKNOWLEDGMENT}

The work was founded in the frame of the project „Biotechnological conversion of glycerol into polyols and dicarboxylic acids" co-financed by the European Union from the European Fund of Regional Development implemented within the Operational Programme - Innovative Economy, 2007-2013.

\section{LITERATURE CITED}

1. Chmielewski, Ł. \& Rodkiewicz, W. (2008, December). International Biofuels Market Status and Prospects, Foundation Programmes for Agriculture (FAPA|), Warsaw 2008 (pp. 1032).

2. Baran, E. (2011, April). The global market for glycerin, Retrieved March 20, 2013, from http://www.chemiaibiznes.com. $\mathrm{pl} /$ artykuly/pokaz/64.html

3. Melcer, A., Klugmann-Radziemska, E. \& Ciunel, K. (2011). Development of glycerin phase from the production of biofuels, Archives of Waste Management and Environmental Protection 13(1), 1-20 from.http://ago.helion.pl

4. Zhou, Z., Du, G., Hua, Z., Zhou, J. \& Chen, J. (2011). Optimization of fumaric acid production by Rhizopus delemar based on the morphology formation. Bioresource Technol. 102(20), 9345-9349. DOI: 10.1016/j.biortech.2011.07.120.

5. Erickson, B., Nelson, J.E. \& Winters, P. (2012). Perspective on opportunities in industrial biotechnology in renewable chemicals. Biotechnol. J. 7(2), 176-185, DOI: 10.1002/biot.201100069.

6. Deng Y., Lee S., Xu Q., Gao M. \& Huang H. (2012). Production of fumaric acid by simultaneous saccharification and fermentation of starchy materials with 2-deoxyglucose-resistant mutant strains of Rhizopus oryzae. Bioresource Technol. 107, 363-367. DOI: 10.1016/j.biortech.2011.11.117.

7. Choi, J.-H., Fukushi, K. \& Yamamoto, K. (2008). A study on the removal of organic acids from wastewaters using nanofiltration membranes. Sep. Purif. Technol. 59(1), 17-25. DOI: 10.1016/j.seppur.2007.05.021.

8. He, Y., Chena, G., Ji, Z. \& Li, S. (2009). Combined UFNF membrane system for filtering erythromycin fermentation broth and concentrating the filtrate to improve the downstream efficiency. Sep. Purif. Technol. 66(2), 390-396. DOI: 10.1016/j. seppur.2008.12.007.

9. Umpucha, C., Galier, S., Kanchanatawee, S. \& Roux-de Balmann, H. (2010). Nanofiltration as a purification step in production process of organic acids: Selectivity improvement by addition of an inorganic salt. Process Biochem. 45(11), 1763-1768. DOI: 10.1016/j.procbio.2010.01.015.

10. Schonherr, J. \& Bukovac, M.J. (1972). Dissociation constants of succinic acid 2,2-dimethylhydrazide. J. Agric. Food Chem. 20(6), 1263-1265. DOI: 10.1021/jf60184a023.

11. Kang, S.H. \& Chang, Y.K. (2005). Removal of organic acid salts from simulated fermentation broth containing succinate by nanofiltration. J. Membr. Sci. 246(1), 49-57. DOI: 10.1016/j. memsci.2004.08.014.

12. Mullet, M., Fievet, P., Reggiani, J.C. \& Pagetti, J. (1997). Surface electrochemical properties of mixed oxide ceramic membranes: Zeta-potential and surface charge density. J. Membr. Sci. 123(2), 255-265. DOI: 10.1016/S0376-7388(96)00220-7. 